BMJ Paediatrics Open

\title{
Predictors of non-fatal violence or assault among adolescents in rural Bangladesh: cross-sectional study
}

\author{
Ikponmwosa Osaghae (i) , ${ }^{1} \mathrm{Md}$ Al-Amin Bhuiyan, ${ }^{2}$ Olakunle Alonge ${ }^{1}$
}

To cite: Osaghae I, Bhuiyan MA-A, Alonge 0. Predictors of non-fatal violence or assault among adolescents in rural Bangladesh: cross-sectional study. BMJ Paediatrics Open 2020;4:e000676. doi:10.1136/ bmjpo-2020-000676

\section{- Additional material is} published online only. To view please visit the journal online (http://dx.doi.org/10.1136/ bmjpo-2020-000676).

Received 4 March 2020 Revised 15 April 2020 Accepted 20 April 2020

\section{Check for updates}

(C) Author(s) (or their employer(s)) 2020. Re-use permitted under CC BY-NC. No commercial re-use. See rights and permissions. Published by BMJ.

${ }^{1}$ Department of International Health, Johns Hopkins Bloomberg School of Public Health, Baltimore, Maryland, USA

${ }^{2}$ Department of IDRC-B, Centre for Injury Prevention and Research Bangladesh, Dhaka, Bangladesh

Correspondence to Dr Ikponmwosa Osaghae; iosagha2@jhu.edu

\section{ABSTRACT}

Objective To determine the predictors of non-fatal violence or assault among adolescents in rural Bangladesh to inform evidence-based interventions.

Design Cross-sectional study.

Setting Household survey and national census in 51 unions of rural Bangladesh.

Participants, methods and main outcome 213782 adolescents aged 11-19 years who reported violence during a population-based survey in 2013. We used logistic regression to determine the prevalence of factors that predict non-fatal forms of violence or assaults among adolescents. Assault or violence was defined as all injuries inflicted directly by another person or resulting from collateral impact over a 6 -month recall period.

Results $457(0.21 \%)$ cases of violence or assault were reported. The prevalence of violence was lower among female adolescents compared with males (PR: $0.60,95 \% \mathrm{Cl} 0.47$ to $0.78, p<0.001$ ). Compared with the lowest socioeconomic quintile, being in a higher quintile was associated with lower prevalence of violence, with a $39 \%$ decrease in the adjusted prevalence of violence among adolescents in highest compared with lowest socioeconomic index (PR: $0.61,95 \% \mathrm{Cl} 0.44$ to 0.84 ). The adjusted prevalence of violence in Chandpur and Comilla districts was 7.30 times and 7.27 times higher respectively than the prevalence of violence in Sirajganj (PR: 7.30, 95\% Cl 4.07 to 13.10 and PR: $7.27,95 \% \mathrm{Cl} 3.56$ to 14.84 , respectively). There was no significant difference in the adjusted prevalence of violence occurring in school compared with home (PR: $1.19,95 \% \mathrm{Cl} 0.85$ to 1.69 ).

Conclusion Male adolescents may be at an increased risk of suffering violence, and socioeconomic factors and place (districts) are strong predictors of adolescent violence among a selected population in rural Bangladesh. These findings are important in guiding interventions to address the burden of violence among adolescents in communities with similar demographics as our study population. Further research is needed to identify the actual burden of violence among adolescents at national level and to establish an effective violence prevention programme across Bangladesh.

\section{INTRODUCTION}

Violence is 'the intentional use of physical force or power, threatened or actual, against oneself, or against an individual, group or community that either results in or has a high likelihood of resulting in injury,

\section{What is known about the subject?}

Interpersonal violence is the second most prevalent cause of death in older adolescent males.

- For every recorded death due to violence, many more sustain non-fatal injuries.

- Victims of violence are subject to physical, social and psychological trauma and may further perpetrate violence against others with health and economic burden on communities.

\section{What this study adds?}

Violence is more prevalent among adolescent males and those in the lowest socioeconomic quintile.

- There is an association between place (districts) and violence in rural Bangladesh with adolescents living in Chandpur or Comilla having higher risk of violence.

death, psychological harm, maldevelopment or deprivation'. Mortality from violence, including homicides, is the fourth leading cause of death among young adults aged 10-29 years with $43 \%$ of global homicides occurring in this age group. ${ }^{2}$ Daily, tens of thousands continue to be victims of nonfatal violence across the world with resultant physical, sexual and psychological abuse, most of which are never reported. ${ }^{1}$ Victims of violence or assault may further perpetrate more violence against others with health and economic burden on communities. ${ }^{2}$ While global data are not available for the medical and loss of productivity costs associated with violence, these costs amount to approximately US $\$ 3.4$ billion annually in the USA. ${ }^{3}$

Adolescence typically refers to the age between 10 and 19 years. ${ }^{4}$ This phase is crucial in the development of a child because they transition into adult life at this phase and are more vulnerable to violence. ${ }^{4}$ About 82000 violence-related deaths occurred among adolescents in 2015 with interpersonal violence being the second most prevalent 
cause of death in older adolescent males, after road traffic accident globally. ${ }^{4}$ While it is not uncommon for strangers or acquaintances to perpetrate violence, there is evidence to show that most victims of violence are closely related to their perpetrators. ${ }^{45}$ The object used to inflict violence may include blunt objects, body parts (eg, fist), stick, knife, acid and firearm. ${ }^{16}$ Also, there is wide variation in the setting or location where violence can occur. This includes the home, neighbourhood, school, outside of school and workplace. ${ }^{4}$

In Bangladesh, the burden of fatal and non-fatal injuries is huge with an annualised injury morbidity rate of 18002 per 100000 population. Those aged $10-17$ years account for $17 \%$ of injury morbidity, and violence accounts for $3 \%$ of the injury morbidity among this age group. ${ }^{7}$ Available studies on adolescent violence in Bangladesh have focused mainly on violence against women and girls, intimate partner violence and sexual violence. ${ }^{189}$ Some studies have also shown increased violence among unmarried adolescents in rural Bangladesh. ${ }^{10}{ }^{11}$ However, there are sparse population data on the predictors of violence among adolescents in rural Bangladesh, and other low/ middle-income countries (LMICs). Population-based surveys have been found to be vital to fully capture the true burden and consequences of both fatal and nonfatal violence. ${ }^{1}$ In this study, we analysed data from a large population-based survey in rural Bangladesh to examine the predictors of violence among adolescents aged 11-19 years.

\section{METHODS}

\section{Data source}

This study used data from the Saving of Lives from Drowning (SoLiD) project, a household census and baseline survey conducted using a cross-sectional study design in rural Bangladesh between June and November 2013. Detailed description of the tool, data collection method and procedure for the SoLiD household survey has been previously reported. ${ }^{7} 12$ The

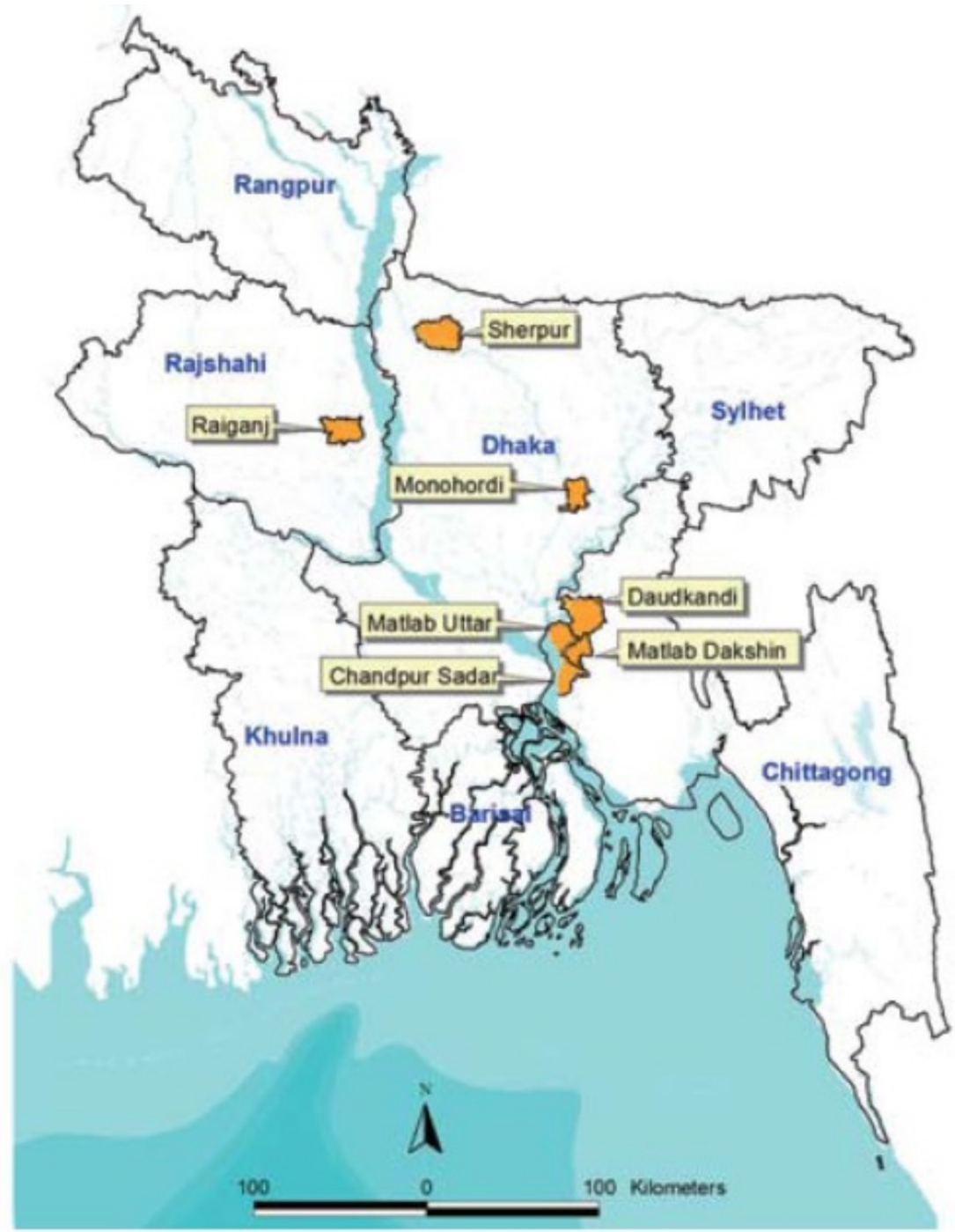

Figure 1 Map of Saving of Lives from Drowning study sites in Bangladesh. ${ }^{14}$ Source: geographic information system unit, International Center for Diarrheal Disease and Research, Bangladesh. 


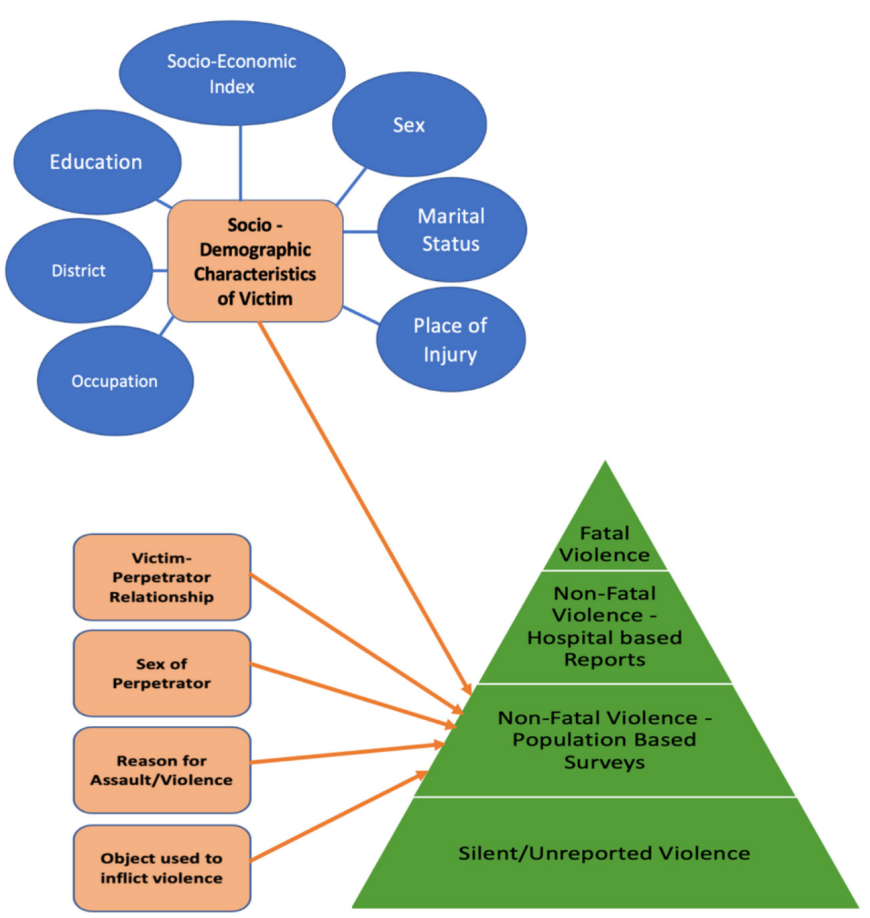

Figure 2 Conceptual framework describing relationship between various predictors and non-fatal violence. Figure adapted from Global Status Report on Violence Prevention, 2014. ${ }^{1}$

census covered 51 unions from 7 purposively selected subdistricts of rural Bangladesh (figure 1). ${ }^{14}$ The 51 unions were selected to exclude unions with history of major injury prevention programme. Data on sociodemographic characteristics and non-fatal injuries were collected by an interviewer administered questionnaire from all households in the 51 unions. ${ }^{14}$ Non-fatal injury was defined as any household member who sought treatment or lost at least 1 workday or could not go to school for at least 1 day due to an injury event, for events occurring in the previous 6 months period from the date of the interview.

For this study, we extracted information on adolescents, defined as all those aged 11-19 years, from the SoLiD census. This yielded a study population of 213782 adolescents from 270387 households in rural Bangladesh. We hypothesised that the following explanatory variables, sociodemographic characteristics, location of event, sex of perpetrator, victim-perpetrator relationship, kind of object used to inflict harm and reason/circumstance of assault, are associated with violence in adolescents (figure 2). 12571115

\section{Patient and public involvement}

During the design of the survey tools and protocol, meetings were held involving local partners, government officials and researchers in Bangladesh to discuss existing gaps and modalities for implementation of the survey. Instruments were modified to accommodate the needs of the Bangladeshi population.

\section{Data analysis}

The dependent variable of interest was physical violence which was defined as all injuries inflicted directly by another person or resulting from collateral impact. This was treated as a binary variable (experience of physical violence vs no violence). Some respondents reported multiple occurrences of violence, and online supplementary table 1 shows the frequency of multiple occurrences of physical violence in the previous 6 months. Less than $11 \%$ of adolescents reported multiple occurrences of physical violence; hence, only the first case of physical violence reported by each adolescent was used in our final analysis to determine the predictors of physical violence. We operationalised our independent variables (sex, marital status, socioeconomic index, occupation, education, district, location of event, sex of perpetrator, victim-perpetrator relationship, kind of object used to inflict harm and reason/circumstance of assault) as categorical variables, and described the distribution of these variables stratified by our dependent variable (violence vs no violence) using simple proportion and a $\chi^{2}$ test. A total of $174(0.08 \%)$ observations were missing information on the variable 'occupation'. These were retained in the dataset; however, a complete case analysis was conducted. Multicollinearity among our covariates was assessed using the variance inflation factor. Variables found to be collinear were further assessed and only one of the collinear variables selected in order to increase precision in our model. Simple logistic regression was used to estimate the prevalence OR of physical violence among adolescents in rural Bangladesh. Given that the prevalence of violence for all ages in rural Bangladesh population is less than $10 \%,^{7}$ the prevalence OR from a logistic regression approximates the prevalence ratio $(\mathrm{PR}) .{ }^{16} \mathrm{~A}$ univariable and multivariable logistic regression was used to determine the PR of violence among adolescents. All analyses were conducted in Stata/IC V.15.1. ${ }^{17}$ Two-sided $p$ values with the level of significance set at 0.05 based on Wald tests were considered statistically significant.

\section{RESULTS}

A total of $457(0.21 \%)$ cases of physical violence were reported among 213782 adolescents between the ages of 11-19 years from rural Bangladesh in 2013. The mean age for adolescents reporting physical violence was 15.2 years. Forty-six (10.07\%) of violence cases reported occurred in school. There was a statistically significant difference in the gender distribution, socioeconomic index, district and location of injury among those who reported violence compared with those who reported no violence (table 1 ).

In table 2, out of the 457 adolescents who were victims of physical violence, quarrel/fight was the the most common reason reported for violence $(92.56 \%)$ followed by burglary $(3.28 \%)$. Friends or acquaintances were the most commonly reported perpetrators of violence $(31.73 \%)$. Physical violence by known non-relatives 
Open access

Table 1 Baseline sociodemographic characteristics for adolescents (11-19 years)

\begin{tabular}{|c|c|c|c|}
\hline \multirow[b]{2}{*}{ Baseline characteristics } & \multirow{2}{*}{$\begin{array}{l}\text { Violence } \\
n=457\end{array}$} & \multirow{2}{*}{$\begin{array}{l}\text { No violence } \\
n=213325\end{array}$} & \multirow[b]{2}{*}{$P$ value } \\
\hline & & & \\
\hline \multicolumn{4}{|l|}{ Sex of victim, n (\%) } \\
\hline Male & $346(75.71)$ & $107553(50.42)$ & 0.000 \\
\hline Female & 111 (24.29) & $105772(49.58)$ & \\
\hline \multicolumn{4}{|l|}{ Marital status n (\%) } \\
\hline Married & $27(5.91)$ & $18241(8.55)$ & 0.138 \\
\hline Never married & 359 (78.56) & $168222(78.86)$ & \\
\hline Divorced & $1(0.22)$ & $262(0.12)$ & \\
\hline Widowed & $0(0.00)$ & $98(0.05)$ & \\
\hline Separated & $1(0.22)$ & $158(0.07)$ & \\
\hline Not applicable & $69(15.10)$ & 26344 (12.35) & \\
\hline \multicolumn{4}{|l|}{ Education n (\%) } \\
\hline No education & $23(5.03)$ & $10996(5.15)$ & 0.22 \\
\hline Primary & 201 (43.98) & 81827 (38.36) & \\
\hline Secondary & $208(45.51)$ & $108044(50.65)$ & \\
\hline A levels & $25(5.47)$ & $12067(5.66)$ & \\
\hline College & $0(0.00)$ & $390(0.18)$ & \\
\hline Advanced/professional degree & $0(0.00)$ & $1(0.00)$ & \\
\hline \multicolumn{4}{|l|}{ Occupation n* (\%) } \\
\hline Agriculture & $10(2.19)$ & $3320(1.56)$ & 0.232 \\
\hline Business & $10(2.19)$ & $2916(1.37)$ & \\
\hline Skilled labour (professional) & $30(6.56)$ & $11453(5.37)$ & \\
\hline Unskilled/domestic (unskilled) & $12(2.63)$ & 4077 (1.91) & \\
\hline Rickshaw/bus (transport worker) & $5(1.09)$ & $1198(0.56)$ & \\
\hline Students & $327(71.55)$ & $157305(73.80)$ & \\
\hline Retired/unemployed/housewife & $62(13.57)$ & $31370(14.72)$ & \\
\hline Not applicable (others) & $1(0.22)$ & $1512(0.71)$ & \\
\hline \multicolumn{4}{|l|}{ Socioeconomic Index n (\%) } \\
\hline Lowest & $87(19.04)$ & $32482(15.23)$ & 0.041 \\
\hline Low & $88(19.26)$ & 41936 (19.66) & \\
\hline Middle & $91(19.91)$ & $46385(21.74)$ & \\
\hline High & 114 (24.95) & $47885(22.45)$ & \\
\hline Highest & $77(16.85)$ & 44637 (20.92) & \\
\hline \multicolumn{4}{|l|}{ District n (\%) } \\
\hline Chandpur & 345 (75.49) & $114591(53.72)$ & 0.000 \\
\hline Comilla & $23(5.03)$ & $5057(2.37)$ & \\
\hline Sirajganj & $12(2.63)$ & $16777(7.86)$ & \\
\hline Sherpur & $27(5.91)$ & $38528(18.06)$ & \\
\hline Narshindi & $50(10.94)$ & 38372 (17.99) & \\
\hline \multicolumn{4}{|l|}{ Place of injury $n \dagger(\%)$} \\
\hline Home & $198(43.33)$ & $5899(40.68)$ & 0.000 \\
\hline School & $46(10.07)$ & $894(6.17)$ & \\
\hline Other playground & $46(10.07)$ & $1206(8.32)$ & \\
\hline Roads/highway/railway station & 99 (21.66) & $3304(22.78)$ & \\
\hline Agricultural field & $31(6.78)$ & 1389 (9.58) & \\
\hline Workplace & $15(3.28)$ & $547(3.77)$ & \\
\hline Others & $22(4.81)$ & 1262 (8.70) & \\
\hline
\end{tabular}

*One hundred and seventy-four observations were missing for occupation. These were left in the data set as it accounted for only $0.08 \%$ of the total observations.

†This category was based only on the population reporting violence $(\mathrm{N}=457)$ under the 'violence' column, and other types of injury ( $N=14501)$ under the 'no-violence' column.

accounted for $22.10 \%$ of cases while strangers were involved in $7.66 \%$ of violent cases. About $86 \%$ of violence was perpetrated by males. In terms of the object used to inflict violence, stick/club was the the most common object $(41.36 \%)$ reported, following by use of person/ body (eg, fist) in $38.95 \%$ of cases. 
Table 2 Distribution of other baseline characteristics predicting violence

\begin{tabular}{|c|c|}
\hline & Violence \\
\hline Baseline characteristics & $n=457^{*}$ \\
\hline \multicolumn{2}{|l|}{ Reason for assault or violence $\mathrm{n}(\%)$} \\
\hline Quarrel/fight & $423(92.56)$ \\
\hline Burglary & $15(3.28)$ \\
\hline Committing a crime (other than above) & $11(2.41)$ \\
\hline Do not know & $2(0.44)$ \\
\hline Others & $6(1.31)$ \\
\hline \multicolumn{2}{|l|}{ Victim-perpetrator relationship n (\%) } \\
\hline Spouse & $25(5.47)$ \\
\hline Father & $10(2.19)$ \\
\hline Mother & $14(3.06)$ \\
\hline Son/daughter & $2(0.44)$ \\
\hline Brother/sister & $38(8.32)$ \\
\hline Grandparents & $6(1.31)$ \\
\hline Other relatives & $65(14.22)$ \\
\hline Friends/acquaintance & $145(31.73)$ \\
\hline Colleague & $7(1.53)$ \\
\hline Known (non-relatives) & $101(22.10)$ \\
\hline Stranger & $35(7.66)$ \\
\hline Others & $8(1.75)$ \\
\hline Do not know & $1(0.22)$ \\
\hline \multicolumn{2}{|l|}{ Sex of perpetrator $\mathrm{n}(\%)$} \\
\hline Male & $392(85.78)$ \\
\hline Female & $65(14.22)$ \\
\hline \multicolumn{2}{|l|}{ Object used to inflict violence $\mathrm{n}(\%)$} \\
\hline Stick/club & $189(41.36)$ \\
\hline Knife/cutting/tool & $29(6.35)$ \\
\hline Fire & $0(0.00)$ \\
\hline Gun/firearm & $1(0.22)$ \\
\hline Acid & $0(0.00)$ \\
\hline Person/body parts (eg, fist) & $178(38.95)$ \\
\hline Others & $60(13.13)$ \\
\hline
\end{tabular}

*Only 457 individuals with violence reported on reason for violence, victim-perpetrator relationship, sex of perpetrator and object used to inflict violence.

In table 3, we found a significant association between sex of the victim and non-fatal violence with the unadjusted prevalence of violence being $67 \%$ lower in females compared with males (Prevalence Ratio (PR): 0.33, $95 \%$ CI 0.26 to 0.40$)$. This remained significantly lower (PR: $0.60,95 \%$ CI 0.47 to 0.78 ) after adjusting for other variables as shown in table 3 . Overall, marriage and level of education were not significantly associated with violence among adolescents.

Socioeconomic index was significantly associated with violence in adolescents in Bangladesh. Compared with the lowest socioeconomic quintile, being in a higher quintile was associated with lower prevalence of violence. There was a $27 \%$ decrease in the unadjusted prevalence of violence among adolescents in middle compared with lowest socioeconomic index (PR: $0.73,95 \%$ CI 0.55 to 0.98 ), which remained significantly lower after adjusting for other variables (PR: $0.63,95 \%$ CI 0.46 to 0.85 ). Similarly, there was a $36 \%$ decrease in the unadjusted prevalence of violence among those in the highest socioeconomic index compared with those in the lowest socioeconomic index (PR: $0.64,95 \%$ CI 0.47 to 0.88 ). This also remained significantly lower after adjusting for other variables (PR: $0.61,95 \%$ CI 0.44 to 0.84 ). The district where violence occurred was found to be significantly associated with violence. The adjusted prevalence of violence in Chandpur and Comilla was 7.30 times and 7.27 times higher respectively than the prevalence of violence in Sirajganj (PR: 7.30, 95\% CI 4.07 to 13.10 and PR: 7.27, $95 \%$ CI 3.56 to 14.84 , respectively), after adjusting for sex, socioeconomic status and place of injury.

There was a significant association between location (place of injury) and occurrence of violence. The unadjusted prevalence of violence occurring in the school was $53 \%$ significantly higher than the prevalence of violence in the home (PR: $1.53,95 \%$ CI 1.10 to 2.13). However, the adjusted PR was not significant (PR: 1.19, 95\% CI 0.85 to 1.69 ). The adjusted prevalence of violence occurring in the roads/highway/railway station was 33\% lower compared with prevalence of violence in the home (PR: $0.67,95 \%$ CI 0.52 to 0.87 ).

In table 4 , the relationship between victim and the perpetrator was found to be significantly associated with violence. The unadjusted and adjusted prevalence of physical violence inflicted by spouse, son/daughter, brother/ sister, other relatives, known non-relatives or strangers was significantly lower compared with the prevalence of violence inflicted by friends/acquaintances. Overall, there was no association between object used and prevalence of violence among adolescents. The use of person/ body parts was significantly associated with a $34 \%$ higher prevalence of violence compared with the use of stick or club (PR: $1.34,95 \%$ CI 1.07 to 1.68 ). However, this was not significant after adjusting for reason for violence, victim-perpetrator relationship and sex of the perpetrator (PR: 1.24, 95\% CI 0.98 to 1.57 ).

\section{DISCUSSION}

Our result show that non-fatal violence is common among adolescents in rural Bangladesh with males significantly more affected compared with females even after adjusting for education, occupation, socioeconomic index, district and location of violence event. Several studies have shown that non-fatal injury rates are significantly higher in males across all age groups and also among those with low socioeconomic status or no education, ${ }^{27815}$ and this study is the first to establish similar associations for nonfatal adolescent violence in rural Bangladesh. Most other 
Table 3 Logistic regression analysis

\begin{tabular}{|c|c|c|c|c|}
\hline \multirow[b]{2}{*}{ Predictors } & \multicolumn{2}{|l|}{ Crude } & \multicolumn{2}{|l|}{ Adjusted ${ }^{*}$} \\
\hline & PR (Cl) & $P$ value & PR (Cl) & $P$ value \\
\hline \multicolumn{5}{|l|}{ Sex of victim } \\
\hline Male & Ref & Ref & Ref & Ref \\
\hline Female & 0.33 (0.26 to 0.40$)$ & 0.000 & 0.60 (0.47 to 0.78$)$ & 0.000 \\
\hline \multicolumn{5}{|l|}{ Marital status } \\
\hline Never married & Ref & Ref & Ref & Ref \\
\hline Married & $0.69(0.47$ to 1.03$)$ & 0.066 & 1.06 (0.66 to 1.70$)$ & 0.809 \\
\hline \multicolumn{5}{|l|}{ Education } \\
\hline No education & Ref & Ref & Ref & Ref \\
\hline Primary & $1.17(0.76$ to 1.81$)$ & 0.466 & 0.93 (0.59 to 1.49$)$ & 0.773 \\
\hline Secondary & 0.92 (0.59 to 1.42$)$ & 0.706 & 1.05 (0.56 to 1.93$)$ & 0.714 \\
\hline A levels & 0.99 (0.56 to 1.75$)$ & 0.974 & 2.24 (0.56 to 1.96$)$ & 0.883 \\
\hline \multicolumn{5}{|l|}{ Occupation } \\
\hline Students & Ref & Ref & Ref & Ref \\
\hline Agriculture & 1.45 (0.77 to 2.72$)$ & 0.249 & 1.37 (0.70 to 2.67$)$ & 0.362 \\
\hline Business & 1.65 (0.88 to 3.10$)$ & 0.120 & 1.74 (0.90 to 3.38$)$ & 0.100 \\
\hline Rickshaw/bus (transport worker) & 2.01 (0.83 to 4.86$)$ & 0.109 & 1.28 (0.51 to 3.24$)$ & 0.595 \\
\hline Retired/unemployed/housewife & 0.95 (0.72 to 1.25$)$ & 0.716 & 1.08 (0.78 to 1.51$)$ & 0.636 \\
\hline \multicolumn{5}{|l|}{ Socioeconomic Index } \\
\hline Lowest & Ref & Ref & Ref & Ref \\
\hline Low & 0.78 (0.58 to 1.05$)$ & 0.107 & 0.73 (0.54 to 0.99$)$ & 0.045 \\
\hline Middle & 0.73 (0.55 to 0.98$)$ & 0.038 & 0.63 (0.46 to 0.85$)$ & 0.003 \\
\hline High & 0.89 (0.67 to 1.18$)$ & 0.408 & 0.76 (0.57 to 1.02$)$ & 0.069 \\
\hline Highest & 0.64 (0.47 to 0.88$)$ & 0.005 & 0.61 (0.44 to 0.84$)$ & 0.003 \\
\hline \multicolumn{5}{|l|}{ District } \\
\hline Sirajganj & Ref & Ref & Ref & Ref \\
\hline Chandpur & 4.21 (2.37 to 7.49$)$ & 0.000 & 7.30 (4.07 to 13.10$)$ & 0.000 \\
\hline Comilla & 6.36 (3.16 to 12.79$)$ & 0.000 & 7.27 (3.56 to 14.84$)$ & 0.000 \\
\hline Sherpur & 0.98 (0.50 to 1.93$)$ & 0.953 & 1.84 (0.93 to 3.66$)$ & 0.081 \\
\hline Narshindi & 1.82 (0.97 to 3.42$)$ & 0.062 & 3.16 (1.67 to 6.00$)$ & 0.000 \\
\hline \multicolumn{5}{|l|}{ Place of Injury } \\
\hline Home & Ref & Ref & Ref & Ref \\
\hline School & 1.53 (1.10 to 2.13$)$ & 0.011 & 1.19 (0.85 to 1.69$)$ & 0.314 \\
\hline Other playground & 1.14 (0.82 to 1.58$)$ & 0.443 & 0.86 (0.61 to 1.22$)$ & 0.398 \\
\hline Roads/highway/railway station & $0.89(0.70$ to 1.14$)$ & 0.364 & 0.67 (0.52 to 0.87$)$ & 0.003 \\
\hline Agricultural field & 0.66 (0.45 to 0.98$)$ & 0.037 & 0.60 (0.40 to 0.89$)$ & 0.012 \\
\hline Workplace & 0.82 (0.48 to 1.39$)$ & 0.457 & 0.55 (0.31 to 0.97$)$ & 0.040 \\
\hline Others $†$ & 0.52 (0.33 to 0.81$)$ & 0.004 & 0.39 (0.25 to 0.61$)$ & 0.000 \\
\hline
\end{tabular}

*Prevalence ratio (PR) from the logistic regression model was adjusted for sex, marital status, occupation, education, socioeconomic index, district and place of violence.

†Others include: industry, factory, workshop, market or bazaar, office, construction area, trees or cowshed.

studies on violence in Bangladesh have focused on sexual or intimate partner violence, and have reported that sexually harassing behaviours were significantly higher among Bangladeshi adolescent girls with secondary or higher level of education. ${ }^{10}$ Across all age and sex groups, non-fatal injuries broadly were previously reported highest among rickshaw pullers and bus drivers, agricultural workers and unskilled labourers. ${ }^{7}$ However, our study found no association between violence in adolescents and occupation which may be due to the limited 
Table 4 Logistic regression analysis

\begin{tabular}{|c|c|c|c|c|}
\hline \multirow[b]{2}{*}{ Predictors } & \multicolumn{2}{|l|}{ Crude } & \multicolumn{2}{|l|}{ Adjusted $^{*}$} \\
\hline & PR (Cl) & $P$ value & PR (Cl) & $P$ value \\
\hline \multicolumn{5}{|l|}{ Reason for assault or violence } \\
\hline Quarrel/fight & Ref & Ref & Ref & Ref \\
\hline Burglary & 0.90 (0.51 to 1.50$)$ & 0.710 & $0.89(0.46$ to 1.71$)$ & 0.733 \\
\hline Committing a crime (other than above) & $0.86(0.45$ to 1.64$)$ & 0.637 & $0.86(0.44$ to 1.67$)$ & 0.652 \\
\hline Do not know & $1.00(0.22$ to 4.56$)$ & 0.995 & $0.66(0.14$ to 3.12$)$ & 0.604 \\
\hline \multicolumn{5}{|l|}{ Victim-perpetrator relationship } \\
\hline Friends/acquaintance & Ref & Ref & Ref & Ref \\
\hline Spouse & $0.30(0.19$ to 0.47$)$ & 0.000 & $0.30(0.19$ to 0.47$)$ & 0.000 \\
\hline Father & $1.17(0.55$ to 2.49$)$ & 0.685 & $1.22(0.57$ to 2.61$)$ & 0.614 \\
\hline Mother & 0.93 (0.50 to 1.75$)$ & 0.823 & 0.97 (0.50 to 1.92$)$ & 0.941 \\
\hline Son/daughter & $0.22(0.51$ to 1.75$)$ & 0.038 & $0.20(0.05$ to 0.85$)$ & 0.032 \\
\hline Brother/sister & $0.41(0.28$ to 0.61$)$ & 0.000 & 0.42 (0.28 to 0.62$)$ & 0.000 \\
\hline Other relatives & 0.50 (0.36 to 0.70$)$ & 0.000 & 0.51 (0.37 to 0.71$)$ & 0.000 \\
\hline Known (non-relatives) & 0.51 (0.39 to 0.68$)$ & 0.000 & $0.52(0.39$ to 0.70$)$ & 0.000 \\
\hline Stranger & 0.55 (0.37 to 0.83$)$ & 0.004 & 0.61 (0.38 to 0.97$)$ & 0.038 \\
\hline Others & 0.37 (0.17 to 0.78$)$ & 0.009 & 0.38 (0.18 to 0.82$)$ & 0.014 \\
\hline \multicolumn{5}{|l|}{ Sex of perpetrator } \\
\hline Male & Ref & Ref & Ref & Ref \\
\hline Female & 0.97 (0.73 to 1.29$)$ & 0.831 & 0.97 (0.71 to 1.33$)$ & 0.846 \\
\hline \multicolumn{5}{|l|}{ Object used to inflict violence } \\
\hline Stick/club & Ref & Ref & Ref & Ref \\
\hline Knife/cutting/tool & 0.93 (0.61 to 1.43$)$ & 0.752 & 0.97 (0.63 to 1.50$)$ & 0.906 \\
\hline Gun/firearm & $0.92(0.11$ to 7.67$)$ & 0.937 & 1.21 (0.13 to 11.67$)$ & 0.869 \\
\hline Person/body parts & 1.34 (1.07 to 1.68$)$ & 0.011 & 1.24 (0.98 to 1.57$)$ & 0.068 \\
\hline
\end{tabular}

*From the logistic regression model was adjusted for reason for violence, victim-perpetrator relationship, sex of the perpetrator and object used to inflict violence.

$\mathrm{PR}$, prevalence ratio.

numbers of some occupational classes in rural setting, including transport workers, rickshaw pullers and bus drivers.

We found that lowest socioeconomic index was significantly associated with violence among adolescents. Although there is no consistency in the definition of socioeconomic index across studies, association between violence and percentage of families living below poverty line has been reported previously. ${ }^{18} 19$ Also, our study shows a significant association between geographical district and occurrence of violence with over sevenfold increase in prevalence of violence in Chandpur and Comilla compared with Sirajganj. Indeed, the statistically significant differences in the prevalence of adolescent violence comparing districts may be due to differences in structural risk factors such as poverty and population density comparing these districts. For example, Chandpur, which has the highest prevalence of adolescent violence among all the districts compared, also has one of the highest poverty headcount ratios $(51 \%)$ compared with Sirajganj (39\%) and Narshindi $(24 \%) .{ }^{20}$ Similarly, the population densities are higher in Chandpur and Comilla (population size of 1227519 and 2043 174, respectively) compared with the other districts (Sirajganj-1 205745 ; Narshindi-527922 and Sherpur-658 627). ${ }^{20}$ These structural risk factors affect violence in several ways as people who live in poverty are likely to be involved in acts of violence because of circumstances they are exposed to such as poor housing, distressed neighbourhood and disrupted families. ${ }^{21}$ It was found that countries having dense population have increased tendency towards crime and violence. ${ }^{2022-24}$ This indicates that population density might be a potential factor for committing more violence among adolescents. ${ }^{20}$ These findings call for concerted efforts by various government agencies and non-governmental organisations including communitybased organisations to put in place schemes that could help identify and address various structural factors that may influence violence, including measures to alleviate the socioeconomic status of persons in districts with high violence experiences. Such collaborative and multisectoral approach could lead to the delivery of affordable 
housing, effective criminal justice system to punish perpetrators of violence, adequate land planning to support healthy physical activities and social services especially for those in the lowest socioeconomic quintile mostly impacted by violence ${ }^{25}$ Furthermore, expanded community engagement involving key stakeholders will help identify practicable strategies and approaches to address adolescent violence in districts that are most impacted.

Currently, education and technology are evolving simultaneously, with adolescents becoming more exposed to modern technologies such as smartphones, tablets and computers which are known to have negative effects on the development and health of children. ${ }^{26}$ While the impact of social media influences on adolescents is expected to be more prevalent in developed countries where internet connectivity is very high, settings in LMICs similar to rural Bangladesh are also catching up on this trend. ${ }^{27} 28$ Adolescents from Comilla and Chandpur may have greater access to modern technologies compared with those from other districts given the higher literacy rates in these districts, $53 \%$ and $56 \%$ in Comilla and Chandpur, respectively (compared with Sirajganj (39\%), Narshindi (49\%) and Sherpur (33\%)). ${ }^{20}{ }^{29}$ As such, adolescents from Comilla and Chandpur are likely to be more exposed to internet and digital technologies, which though are commonly used as learning aids in rural settings, may also increase the exposure of these adolescents to violent and harmful behaviours being portrayed on the internet. According to UNICEF Bangladesh, about $25 \%$ of the children aged 10-17 started to access the digital world when they were below the age of 11 and adolescent boys $(63 \%)$ are more frequent regarding online access and use than girls $(48 \%) .^{29}$ Research indicates that increasing the time on social media is directly associated with aggressive behaviour among adolescents and act as a vector for violence. ${ }^{30} 31$ Therefore, exposure to technologies and social media might be a trigger for violent behaviour among adolescents.

These two districts are also in closer proximity to major urban cities in Bangladesh, and a spillover of violence behaviours from the urban centres into these districts is possible. When urbanisation is rapid and poorly planned, the numbers of unemployed youth increase rapidly resulting in different types of violence and social unrest. ${ }^{32}$ During the last four decades, there has been rapid urbanisation in Bangladesh with migrant population as one of the causes. ${ }^{33}$ An exploratory study conducted in Bangladesh regarding adolescent's exposure to violence showed that a large number of respondents from Comilla were exposed to both low and high levels of violence, sexual harassment and witnessing and/or experiencing sexual and physical violence. Crime statistics 2018 shows that all kind of crimes like robbery, kidnapping, burglary, arms act, smuggling and drug cases are higher in Chittagong division in which both Comilla and Chandpur districts are situated but low in Rajshahi division where Sirajganj district is situated. ${ }^{34}$ Witnessing high levels of violence can affect attitude and perception towards violence and increase the likelihood of further violence and distress. ${ }^{235}$ Exposure to high level of violence could be a factor behind the high prevalence of violence seen in Comilla and Chandpur. In order to elucidate this further, qualitative approach like ethnography should be explored in these districts.

Previous reports show that the proportion of youths attending school is relatively similar across the five districts of Sirajganj (69\%), Narshindi (69\%), Sherpur $(69 \%)$, Comilla $(71 \%)$ and Chandpur $(74 \%) .{ }^{20}$ Hence, school attendance may not be a significant factor to explain violence in rural Bangladesh as found in some other studies. $^{36-38}$

The home settings in rural Bangladesh often include multiple families and households living together in a single settlement, and adolescent violence may be more likely among peers who may not necessarily be family members but live in close proximity within these settlements. This may explain the high prevalence of violence in the home from our study. Previous studies in Bangladesh and other similar settings have shown that community norms that encourage acceptance of physical assault or violence are associated with the perpetration of violence among adolescents, especially community tolerance of physical violence among male adolescents. ${ }^{89} 40$ There is need for implementation of programmes and policies directed at discouraging the community acceptance of violence both at home and in schools settings in rural Bangladesh, as this will help denormalise this attitude and practice. Also, involvement of community leaders to champion campaigns against violence will help reduce the perpetration of violent acts. In addition, interventions to raise the economic status of adolescents should be considered by the government as high socioeconomic quintile has been found to be protective against violence.

\section{LIMITATIONS}

Given that this study was done in a predominantly rural setting, the findings may not be generalisable and nationally representative for Bangladesh. Also, the data are subject to recall bias given that information on violence was self-reported over a 6-month recall window. Similarly, the definition of non-fatal injury over a 6-month window as well as differential recall bias of minor cases or community acceptable forms of violence may have led to underestimation of the true prevalence of non-fatal violence. In addition, misclassification of injuries may have resulted from various forms of information bias, data collection or entry errors, which may have led to misclassification of violence by age or gender. In addition, there may be some confounding by school attendance given that this was not directly adjusted for in the analyses. However, given the large population size covered under this study, these likely biases are expected to be minimised.

\section{CONCLUSION}

We found that male adolescents may be at increased risk of suffering violence in rural Bangladesh. Also, 
socioeconomic factors and place (districts) are strong predictors of adolescent violence in seven selected rural districts of Bangladesh, with higher risk of violence in Chandpur or Comilla. Violence was found to occur more at home and typically involved an acquaintance or friend. The results suggest pertinent directions for public health policies aimed at addressing violence among adolescents and should guide the development and execution of interventions that are directed at those in low socioeconomic class particularly in rural communities with similar demographics as our study population. Moreover, further research is needed to identify the actual burden of violence among adolescents at national level in Bangladesh and to establish an effective violence prevention programme all over the country.

Correction notice This article has been corrected since it was published. Some typographical errors have been corrected.

Twitter Ikponmwosa 0saghae @I0saghae and Md Al-Amin Bhuiyan @al_ aminbhuiyan

Contributors 10 conceived the paper, contributed to the study design and analyses, wrote the first draft, and managed subsequent revisions. MA-AB reviewed the manuscript and contributed to the discussion of results. $\mathrm{OA}$ contributed to the study design, reviewed, edited the manuscript for intellectual content and supervised the study.

Funding The original study and data collection were funded by the Bloomberg Philanthropies under the Saving of Lives from Drowning — SoLiD project.

Map disclaimer The depiction of boundaries on the map(s) in this article does not imply the expression of any opinion whatsoever on the part of BMJ (or any member of its group) concerning the legal status of any country, territory, jurisdiction or area or of its authorities. The map(s) are provided without any warranty of any kind, either express or implied.

Competing interests None declared.

Patient consent for publication Not required.

Ethics approval The protocol was approved by the Ethics Committee of Johns Hopkins Bloomberg School of Public Health, Center for Injury Prevention and Research, Bangladesh and International Center for Diarrheal Disease and Research, Bangladesh. Ethical approval was provided by the Johns Hopkins Bloomberg School of Public Health (approval code: 00004746).

Provenance and peer review Not commissioned; externally peer reviewed.

Data availability statement Data are available upon reasonable request. The final data and accompanying code are available upon reasonable request from oalonge1@jhu.edu.

Open access This is an open access article distributed in accordance with the Creative Commons Attribution Non Commercial (CC BY-NC 4.0) license, which permits others to distribute, remix, adapt, build upon this work non-commercially, and license their derivative works on different terms, provided the original work is properly cited, appropriate credit is given, any changes made indicated, and the use is non-commercial. See: http://creativecommons.org/licenses/by-nc/4.0/.

ORCID iD

Ikponmwosa Osaghae http://orcid.org/0000-0002-7202-7435

\section{REFERENCES}

1 Alexander Butchart, Christopher Mikton. Global status report on violence prevention, 2014. Available: https://www.who.int/violence injury_prevention/violence/status_report/2014/en/

2 WHO. Youth violence, 2016. Available: https://www.who.int/en/ news-room/fact-sheets/detail/youth-violence [Accessed 15 Jan 2019].

3 David-Ferdon CF, Haileyesus T, Liu Y, et al. Nonfatal Assaults Among Persons Aged 10-24 Years - United States, 2001-2015. MMWR Morb Mortal Wkly Rep 2018;67:141-5.
4 United Nations Children's Fund (UNICEF). A familiar face: violence in the lives of children and adolescents, 2017. Available: https://www. unicef.org/publications/files/Violence_in_the_lives_of_children_and_ adolescents.pdf

5 Weizmann-Henelius G, Viemerö V, Eronen M. The violent female perpetrator and her victim. Forensic Sci Int 2003;133:197-203.

6 Brennan IR, Moore SC, Shepherd JP. Non-firearm weapon use and injury severity: priorities for prevention. Inj Prev 2006;12:395-9.

7 Alonge O, Agrawal P, Talab A, et al. Fatal and non-fatal injury outcomes: results from a purposively sampled census of seven rural subdistricts in Bangladesh. Lancet Glob Health 2017:5:e818-27.

8 VanderEnde K, Amin S, Naved RT. Community-Level correlates of physical violence against unmarried female adolescents in Bangladesh. BMC Public Health 2014;14:1027.

9 Parvin K, Sultana N, Naved RT. Disclosure and help seeking behavior of women exposed to physical spousal violence in Dhaka slums. BMC Public Health 2016;16:383-8.

10 Alam N, Roy SK, Ahmed T. Sexually harassing behavior against adolescent girls in rural Bangladesh. $J$ Interpers Violence 2010;25:443-56.

11 Nahar Q, Amin S. Gender, poverty and physical abuse in schools in Bangladesh, 2006.

12 Sharmin Salam S, Alonge O, Islam Ml, et al. The burden of suicide in rural Bangladesh: magnitude and risk factors. Int $J$ Environ Res Public Health 2017;14:1032.

13 Khatlani K, Alonge O, Rahman A, et al. Caregiver supervision practices and risk of childhood unintentional injury mortality in Bangladesh. Int J Environ Res Public Health 2017;14:515.

14 Hyder AA, Alonge $\mathrm{O}, \mathrm{He} \mathrm{S}$, et al. A framework for addressing implementation gap in global drowning prevention interventions: experiences from Bangladesh. J Health Popul Nutr 2014;32:564-76.

15 Khan U, Hisam B, Zia N, et al. Uncovering the burden of intentional injuries among children and adolescents in the emergency department. BMC Emerg Med 2015;15 Suppl 2:S6.

16 Cornfield J. A method of estimating comparative rates from clinical data; applications to cancer of the lung, breast, and cervix. $J$ Natl Cancer Inst 1951;11:1269-75.

17 StataCorp. Stata statistical software: release 15. college station, TX: StataCorp LLC, 2017.

18 Anderson BL, Pomerantz WJ, Gittelman MA. Intentional injuries in young Ohio children: is there urban/rural variation? J Trauma Acute Care Surg 2014;77:S36-40.

19 Sethi D. European report on preventing child maltreatment. World Health Organization, Regional Office for Europe, 2013.

20 The World Bank. Bangladesh interactive poverty maps, 2016. Available: https://www.worldbank.org/en/data/interactive/2016/11/ 10/bangladesh-poverty-maps [Accessed 30 Nov 2019].

21 World Health Organization. Injuries and violence: the facts, 2014. Available: http://www.who.int/iris/handle/10665/149798

22 Crutchfield RD, Wadsworth T. Poverty and violence. In: Heitmeyer W, Hagan J, eds. International Handbook of violence research. Springer, Dordrecht, 2003.

23 Sheykhi MT. Increasing crimes vs. population density in Megacities. Sociology and Criminology 2016;4.

24 David Richard Steinmetz. The pressure cooker: population density and crime, 2016. Available: https://nycdatascience.com/blog/ student-works/pressure-cooker-higher-population-densitiesincrease-crime/

25 California Department of Public Health. Preventing violence in California volume 1: the role of public health. Sacramento, CA: California Department of Public Health, 2017.

26 Mustafaoğlu Rüstem, Zirek E, Yasacı Z, et al. The negative effects of digital technology usage on children's development and health. Addicta: The Turkish Journal on Addictions 2018;5.

27 Bahia K, Suardi S. The state of mobile Internet connectivity, 2019. Available: https://www.gsma.com/mobilefordevelopment/ wp-content/uploads/2019/07/GSMA-State-of-Mobile-InternetConnectivity-Report-2019.pdf

28 FAO. Use of mobile phones by the rural poor: gender perspectives from selected Asian countries. Bangkok: The Food and Agriculture Organization of the United Nations, LIRNEasia, and International Development Research Centre, 2016. http://www.fao.org/3/ai5477e.pdf

29 UNICEF. Adolescents in development, Bangladesh. Available: https://www.unicef.org/bangladesh/en/adolescents-development [Accessed 30 Nov 2019].

30 Huesmann LR. The impact of electronic media violence: scientific theory and research, 2007. Available: http://hdl.handle.net/2027.42/ 83439 
31 Patton DU, Hong JS, Ranney M, et al. Social media as a vector for youth violence: a review of the literature. Comput Human Behav 2014;35:548-53.

32 World Economic Forum. Part 2: risks in focus: City limits: the risks of rapid and unplanned urbanization in developing countries, 2019.

33 Islam N. Urbanization in Bangladesh: recent trends and challenges, 2018. Available: https://www.daily-sun.com/post/345303/2018/10/ 24/Urbanisation-in-Bangladesh:-Recent-Trends-and-Challenges [Accessed 30 Nov 2019].

34 Bangladesh Police. Crime statistics, 2018. Available: https://www. police.gov.bd/en/crime_statistic/year/2018 [Accessed 30 Nov 2019].

35 Ma J, Grogan-Kaylor A, Delva J. Behavior problems among adolescents exposed to family and community violence in Chile. Fam Relat 2016;65:502-16.
36 Bowen NK, Bowen GL. Effects of crime and violence in neighborhoods and schools on the school behavior and performance of adolescents. J Adolesc Res 1999;14:319-42.

37 Benbenishty R, Astor RA, Zeira A, et al. Perceptions of violence and fear of school attendance among junior high school students in Israel. Soc Work Res 2002;26:71-87.

38 Dunne M, Sabates R, Bosumtwi-Sam C, et al. Peer relations, violence and school attendance: analyses of bullying in senior high schools in Ghana. J Dev Stud 2013;49:285-300.

39 Boyle MH, Georgiades K, Cullen J, et al. Community influences on intimate partner violence in India: women's education, attitudes towards mistreatment and standards of living. Soc Sci Med 2009;69:691-7.

40 Koenig MA, Stephenson R, Ahmed S, et al. Individual and contextual determinants of domestic violence in North India. Am J Public Health 2006;96:132-8. 